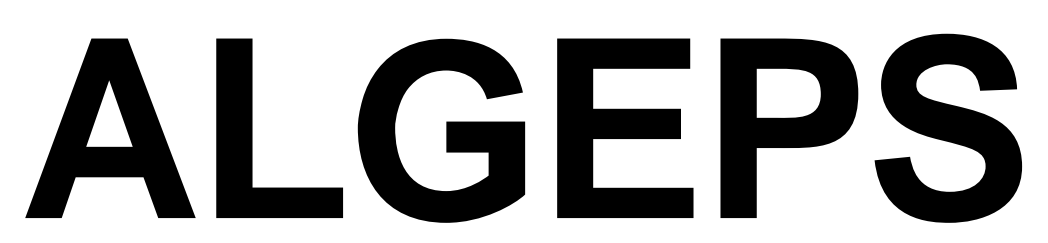

REVISTA DE GEOLOGIA, SÈRIE B no 632 - Maig del 2013

ISSN $1132-7014$

D.L.B. 28.178 - 92

10 pàgines

\title{
RECORREGUT GEOLÒGIC I MINERALÒGIC PER LES COMARQUES DE LA RIBAGORÇA I DEL PALLARS JUSSÀ: DES DE BENAVARRI AL PONT DE MONTANYANA I A SANT ESTEVE DE LA SARGA
}

Josep M. Mata-Perelló i Joaquim Sanz Balagué 



\section{RECORREGUT GEOLÒGIC I MINERALÒGIC PER LES COMARQUES DE LA RIBAGORÇA I DEL PALLARS JUSSÀ: DES DE BENAVARRI AL PONT DE MONTANYANA I A SANT ESTEVE DE LA SARGA ${ }^{1}$}

Per Josep M. MATA-PERELLÓ i Joaquim SANZ BALAGUË

\section{ADVERTIMENT PREVI}

Com en altres recorreguts de RECERCA GEOLÒGICA I MINERALÒGICA ..., si es disposa del temps suficient, poden efectuar-se passant per totes les parades i filloles. En cas contrari, recomanem prescindir de les anomenades PARADES - CONDICIONALS.

També cal tenir en conte que una part del recorregut final de l'itinerari, es realitzarà per camins de terra, per la qual cosa caldrà prendre les degudes precaucions,

Cal tenir, com sempre, una cura molt especial de respecte a la natura, al llarg de tot el recorregut de l'itinerari, i també fora d'ell.

\section{BREU INTRODUCCIÓ}

En aquesta ocasió, el recorregut de l'itinerari discorrerà, en la seva quasi totalitat pel Sistema Pirinenc, i més concretament ho farà per la seva Unitat Sudpirinenca Central (tradicionalment coneguda amb el nom de les Serres Exteriors Prepirinenques). Tot i així, la pràctica totalitat del recorregut transitarà pels sectors septentrionals del Mantell del Montsec, entre les poblacions de Benavarri i Sant Esteve de la Sarga.

També cal dir, que el recorregut de l'itinerari discorrerà per dues de les comarques que constitueixen la Regió de Lleida; concretament per la comarca de la Ribagorça Oriental (avui inclosa a la comarca de la Ribagorça) i per la comarca del Pallars Jussà, iniciant-se a la primera i finalitzant a la segona.

\footnotetext{
1 En este escrito se ha optado por utilizar los nombres de los topónimos en las modalidades dialectales utilizadas en la zona. Sin embargo, al final (tras la bibliografía) se ha colocado un esquema de equivalencias entre el nombre utilizado y el castellano, de uso común en Aragón. Así: VER: APENDIX TAULA D’EQUIVALÈNCIES DELS TERMES TOPONÓMICS DE LA ZONA (PAG. 16)
} 


\section{OBJECTIUS FONAMENTALS D'AQUEST ITINERARI}

Els objectius fonamentals que es pretenen aconseguir en aquest itinerari, es poden concretar en els següents aspectes generals:

1.- Observació i descripció dels materials mesozoics (fonamentalment del Cretàcic) del Mantell del Montsec; que trobarem fonamentalment entre les poblacions de Benavarri i Sant Esteve de la Sarga.

2.- Observació de l'estructura del Mantell del Montsec, que anirem trobant al llarg de tot el recorregut de l'itinerari.

3.- Observació i reconeixement, si s'escau, de diferents mineralitzacions situades a diversos indrets del recorregut de l'itinerari.

4.- Observació, si s'escau, de les explotacions mineres desenvolupades al llarg del recorregut de l'itinerari.

5.- Observació de les restauracions dutes a terme sobre les explotacions mineres esmentades a l'apartat anterior.

6.- Observació dels indrets relacionats amb el Patrimoni Geològic i amb el Patrimoni Miner, que es vagin trobant al llarg del recorregut de l'itinerari.

\section{ANTECEDENTS BIBLIOGRÀFICS}

Pel que fa al recorregut del present itinerari, no existeix cap antecedent concret, de tipus bibliogràfic referent a la totalitat del recorregut del mateix. Les úniques excepcions, molt parcials, les trobarem als treballs de MATA - PERELLÓ (2005a, 2005b i 2008).

Tanmateix, pel que fa a la descripció de les mineralitzacions, cal parlar del treball de MATA-PERELLÓ (1991), relatiu a les mineralitzacions catalanes en general; i en particular, pel que fa al capítol dedicat a la comarca de la Noguera. I, finalment, pel que fa a l'estructura geològica de la zona per la qual discorre l'itinerari, farem esment dels treballs generalistes de: GUIMERÀ et altri (1982) i de RIBA et altri (1976).

Tots aquests treballs referenciats, i d'altres, figuren esmentats per ordre alfabètic a l'apartat dedicat a la BIBLIOGRAFIA.

\section{RECORREGUT DE L'ITINERARI}

El recorregut de l'itinerari i situarà entre dues comarques: la de la Ribagorça (on començarà, per immediacions de Benavarri) i la del Pallars Jussà (per on finalitzarà, prop de Sant Esteve de la Sarga).

En aquet itinerari el recorregut seguirà inicialment la carretera $\mathrm{N}-230$, passat per les immediacions de Tolba i de Viacamp, fent-se algunes aturades prop d'aquestes poblacions. Tot 
seguit, es farà una fillola, per tal d'anar a Xiriveta (Chiriveta), per on s'efectuaran diverses aturades.

Tot seguit, després d'arribar a la N-230, el recorregut es dirigirà cap el Sud, anant cap a: Castissent, Alsamora i Sant Esteve de la Sarga. En arribar a aquest darrer poble finalitzarà el recorregut.

\section{DESCRIPCIÓ DE L'ITINERARI}

Com de costum, estructurarem el recorregut de l'itinerari en una sèrie de PARADES, que tot seguit anirem veient. En cadascuna d'aquestes aturades farem un breu comentari (geològic o mineralògic, segons s'escaigué). En cada cas indicarem, entre parèntesi, el full topogràfic on es troba l'aturada. Finalment, cal dir que el recorregut de l'itinerari s'inclourà dintre dels full $\mathrm{n}^{\circ} \mathbf{2 5 1}$ (dit d'Areny), 252 (o de Tremp), $\mathbf{2 8 9}$ (o de Barbastro) i 290 (dita d'Isona) del "Mapa Topográfico Nacional", realitzats a l'escala 1:50.000 per 1’"Instituto Geográfico y Catastral".

Així, doncs, la relació ordenada de les aturades que formen part d’aquest itinerari és la següent:

PARADA 1. VARIANT SEPTENTRIONAL DE BENAVARRI, (terme municipal de Benavarri, comarca de la Ribagorça). (Full 289).

El recorregut del present itinerari, s'inicia dintre del termes de la població de Benavarri (antiga capital de la Baixa Ribagorça o Ribagorça Oriental, avui incorporada a la comarca la Ribagorza, amb seu central a Gaus (antiga capital de la Ribagorça Occidental). Així, la primera aturada es farà a la part septentrional del municipi.

Aquest indret es troba situat dintre del Mantell del Montsec, als sectors occidentals, on ha perdut sensiblement l'alçada que te més cap a llevant. Així, per arreu afloren els materials mesozoics del Cretàcic i també els terrenys cenozoics de 1'Eocè. Tots de naturalesa eminentment carbonatada.

PARADA 2. MAS DE FALC, (terme municipal de Tolba, comarca de la Ribagorça Oriental / Baixa Ribagorça). (Full 250).

Després de fer la parada anterior, cal anar apropant-nos cap a Tolba. Poc abans d'arribar-hi, en baixar el petit portet del trencall de les Segarres, es trobaran unes granges d'on eix el camí que es dirigeix cap al Mas de Falç. Poc abans d'arribar-hi farem una nova aturada, a uns $5 \mathrm{Km}$ de l'anterior.

En aquest recorregut, poc després de deixar enrere la població de Benavarri, s'han començat a trobar afloraments de nivells detrítics de conglomerats oligocènics. Aquests són discordants amb els materials anteriors, als quals cobreixen. Tenen un clar caràcter postorogènic. Tot i així, en aquest indret es troben uns afloraments dels materials carbonatats mesozoics del Cretàcic. 
Des d'aquest indret, mirant cap al Sud, es pot veure una estreta vall, excavada a la intersecció entre el Riu Queixigar i el Riu Sec. Aquesta vall es la part final del Congost de Ciscar. Com ja hem dit anteriorment, es tracta d'un interessant indret del nostre Patrimoni Geològic. Aquest congost ha estat obert pel riu Queixigar (Cagigar) en travessar els materials carbonatats. És un interesant i vistós congost que s'estén entre les immediacions del poble de Ciscar i l'indret on ara ens trobem, a la part alta del congost. FOTOGRAFÍA 1.

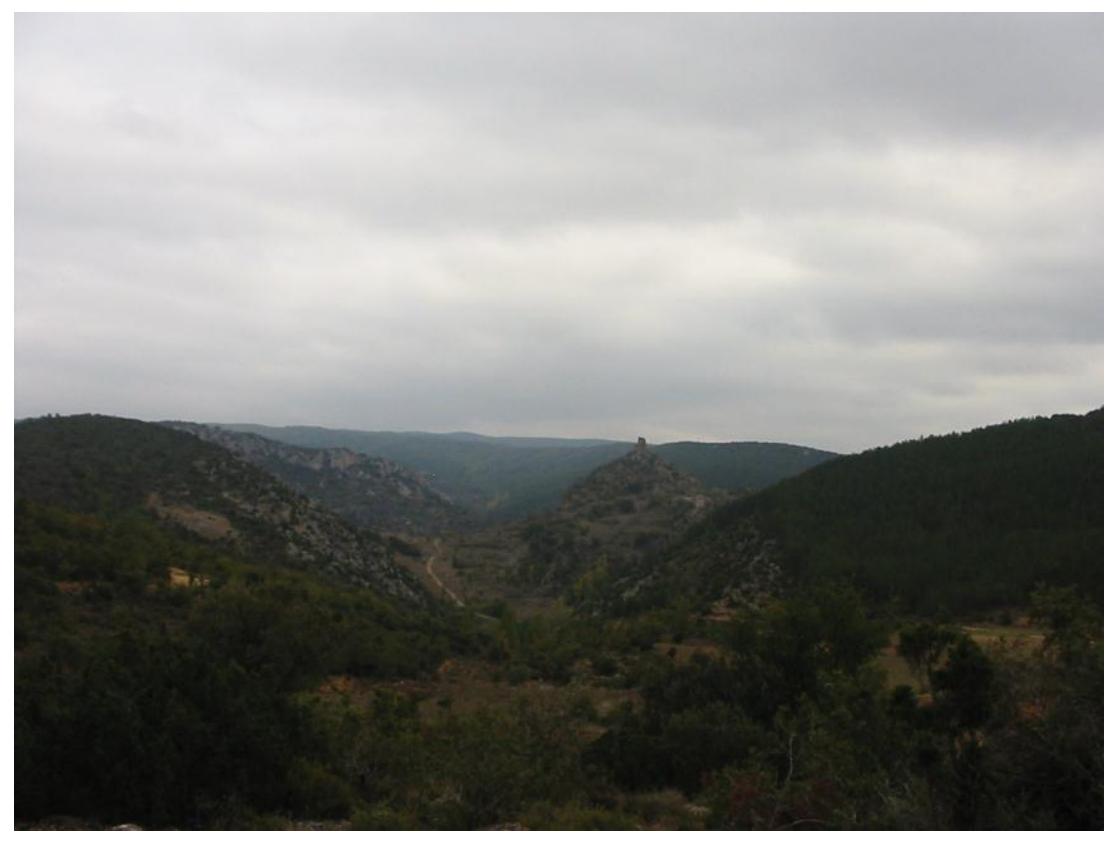

FOTOGRAFIA 1.

Part alta del Congost del riu Queixigar, prop de Tolba

PARADA 3. DESCARREGADOR DELA PEDRERA DE TOLBA, (terme municipal de Tolba, comarca de la Ribagorça). (Full 251).

Des de la parada anterior cal retornar a la carretera $\mathrm{N}-230$, la que hem agafat a la població de Benavarri. En retrobar-la, haurem de continuar el recorregut cap a llevant. Però per les immediacions de l'indret on arribarem a la carretera, ens caldrà fer una altra aturada. A uns 2 Km de l'anterior.

En aquest recorregut, hem tornat a trobar afloraments dels materials esmentats a les aturades anteriors.

Per d'altra banda, a l'indret de l'aturada es fa força palès un descarregador miner. Es tracta d'una de les instal-lacions d'una explotació realitzada a cel obert, per tal d'explotar els materials carbonatats, estrets dels nivells de conglomerats que afloren per arreu. FOTOGRAFIA 2 . 


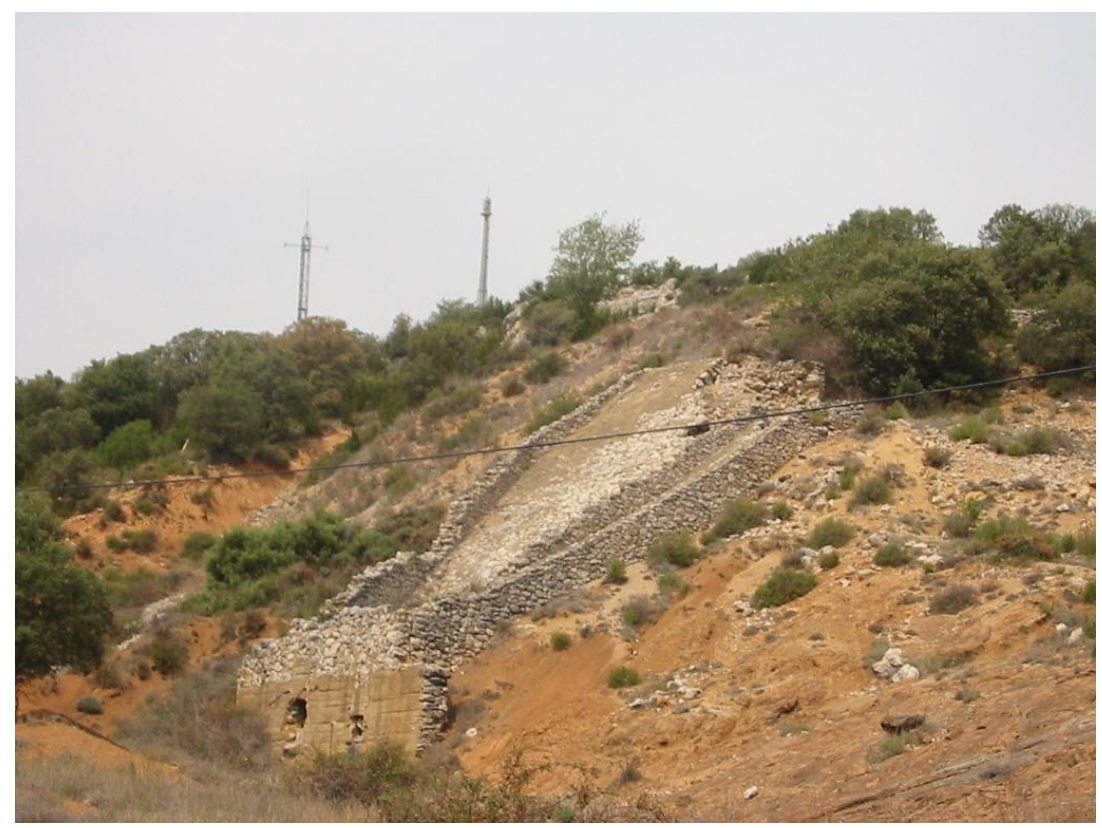

FOTOGRAFIA 2.

Descarregador de Tolba

\section{PARADA 4. CAMÍ DEL CASTELL DE XIRIVETA, (Xiriveta, terme municipal de Viacamp i Llitera, comarca de la Ribagorça). (Full 289).}

Després de realitzar l'aturada anterior, ens caldrà continuar perla carretera $\mathrm{N}-230$, tot anant cap a llevant. Aviat passarem per Tolba (per on sobrepassarem el riu Queixigar) i més enllà per Viacamp. Seguint la carretera, arribarem al trencall de Llitera, que no haurem d'agafar. Posteriorment, des de la carretera N-230, trobarem el trencall (a la dreta de Xiriveta, cap on ens caldrà anar-hi. En arribar-hi, ens caldrà anar cap a les immediacions del seu Castell, per on farem la present aturada, a uns $18 \mathrm{Km}$ de la parada anterior.

En aquest recorregut, ens haurem desplaçat sempre pels sectors septentrionals del Mantell del Montsec, entre afloraments de materials mesozoics (del Cretàcic) i cenozoics (de l'Eocè). Molt sovint, uns i altres es troben recoberts per terrenys detrítics dels conglomerats postorogènics de l’Oligocè.

L'indret de l'aturada, es troba al sector septentrional del Montsec d'Estrall (o de Montgai), dins el Mantell del Montsec. Així, es veuen afloraments dels materials carbonatats cretàcics, recoberts per derrubis de pendent quaternaris.

Des d'aquest lloc, mirant cap al Sud, es pot veure l'impressionant Congost (o Pas) de Monrebei, esculpit per la Noguera Ribagorçana en travessar la Serra del Montsec, deixant a Catalunya el Montsec d'Ager i a l'Aragó l'esmentat Montsec d'Estrall (o de Montgai), en el flanc septentrional estem. FOTOGRAFIA 3.

Aquesta vista es podrà complementar amb la que veurem des de l'altra banda del riu, per les immediacions de Castissent i de l'Alsamora, molt prop de l'esmentat Congost (o Pas) de Monrebei 


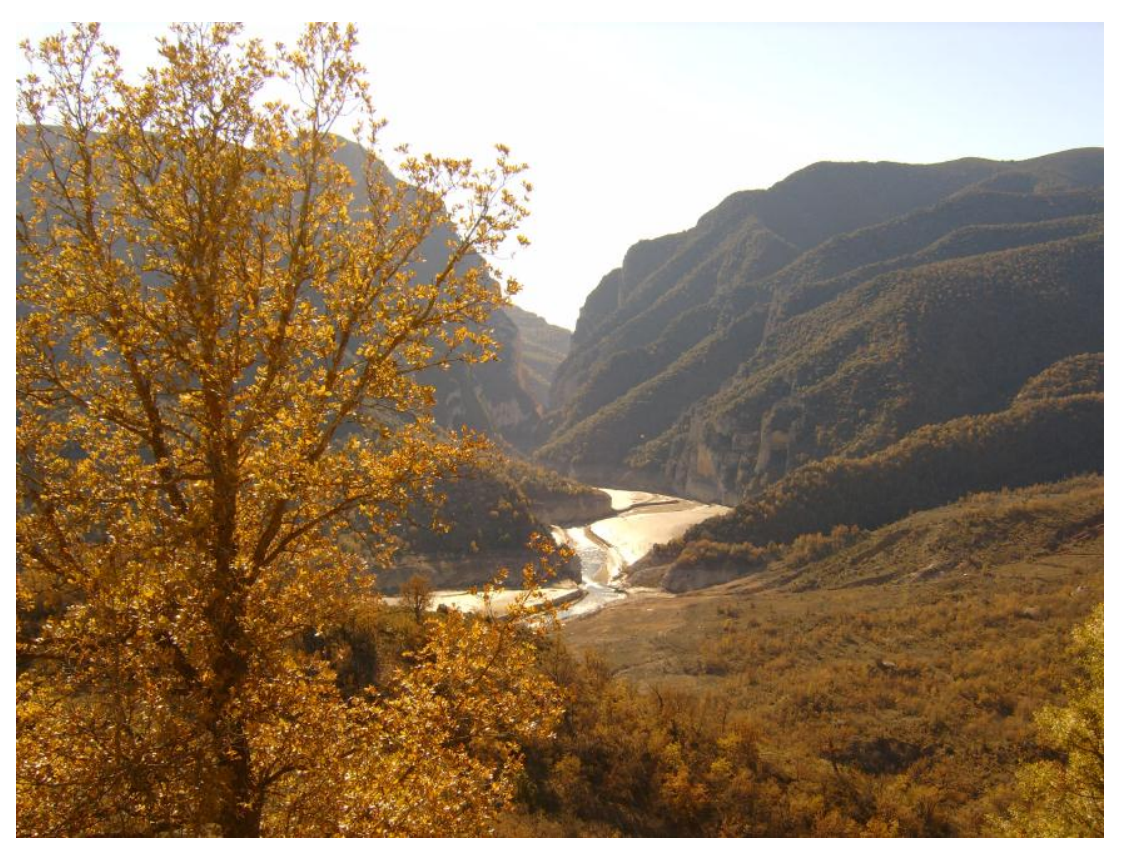

FOTOGRAFIA 3

El Congost (o Pas) de Monrebei, des de el castell de Xiriveta

\section{PARADA 5. IMMEDIACIONS DE CASTISSENT, (terme municipal de Tremp, comarca del Pallars Jussà). (Full 289).}

Després de fer la parada anterior, cal retornar cap a la carretera N-230. En trobar-la, ens caldrà seguir cap a llevant, amb la finalitat d'arribar fins al poble del Pont de Montanyana, per on creurem a l'altre cantó del Noguera Ribagorçana, passant alhora de la comarca de la Ribagorça a la del Pallars Jussà. Tot seguit, ens caldrà seguir breument per la carretera C-1311 (la qual es dirigeix cap a Tremp). Però, ben de seguida, ens caldrà agafar, per la dreta, la carretereta que es dirigeix cap a Castissent i cap a Sant Esteve de la Sarga. En arribar a les immediacions del trencall que se'n va cap el primer poble, farem una nova aturada. Així, haurem recorregut uns $8^{\prime} 5 \mathrm{Km}$, des de la parada anterior.

En aquest recorregut, haurem trobat afloraments dels materials detrítics (fonamentalment de l'Oligocè) que cobreixen als mesozoics dels trams septentrionals del Mantell del Montsec. Molt sovint, sobre aquests materials oligocènics, trobem també els terrenys detrítics del Quaternari.

Des d'aquest indret es pot fer una bona observació del Noguera Ribagorçana. I també dels materials detrítics que arrossega, procedents tant de la Zona Axial Pirenaica com de les Serres Interiors.

PARADA 6. INICI DEL CAMI DEL PAS DE COLLEGATS, (terme municipal de Sant esteve de la Sarga, comarca del Pallars Jussà). (Full 251).

Després de fer la parada anterior, cal continuar per la carretereta, dirigint-nos cap el Sud, cap 1'Estret de Monrebei i també cap el poble d'Alsamora. En arribar al trencall d'aquest poble, ens caldrà continuar cap arribar al Fondo de la Maçana i cap el Pont Penjant. 
En arribar a aquest indret, farem una nova aturada, a uns $5 \mathrm{Km}$ de l'anterior. Tot i que ara, a partir d'aquest indret, podem seguir a peu pel camí que discorre per l'Estret de Monrebei.

En aquest recorregut, hem tornat a trobar afloraments dels materials carbonatats cretàcics, els quals formen part del Mantell del Montsec. Aquests materials es faran molt palesos alhora se seguir el recorregut a peu.

En tot aquest recorregut, especialment als darrers trams, es fa força palès el congost obert pel riu Ribagorçana en travessar la Serra del Montsec (del mantell del mateix nom). També és interessant veure l'obra del camí, obert entre les calcaries, per tal d'afavorir la transhumància que abans es feia pel riu, a les èpoques d'estiatge abans de construir-se l'embassament de Canelles. FOTOGRAFIES 4 i 5

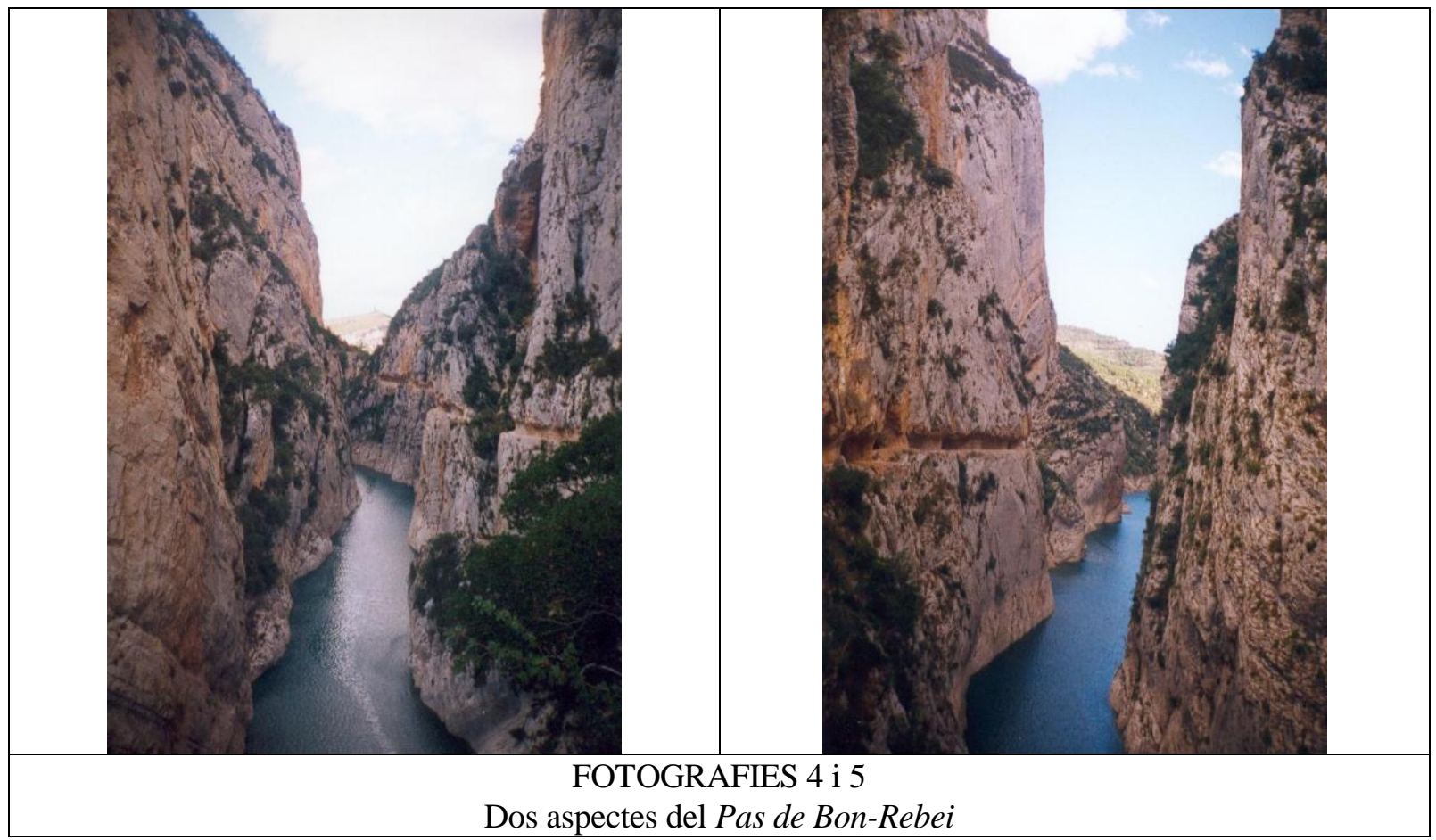

PARADA 7. POBLE DE SANT ESTEVE DE LA SARGA, (terme municipal de Sant esteve de la Sarga, comarca del Pallars Jussà). (Full 251).

Després de fer la parada anterior, cal retornar cap a la cruïlla d'on eix el camí cap el poble d'Alsamora, cap on ens caldrà anar. Tot seguit, haurem de continuar cap el poble de Sant Esteve de la Sarga, En arribar, podem fer una nova aturada. Així, haurem recorregut uns $6 \mathrm{Km}$ més, tres d'ells des d’Alsamora.

En aquest recorregut, haurem circulat en tot moment, entre afloraments dels materials mesozoics del Cretàcic, els quals constitueixen els relleus de la Serra del Montsec, on ens trobem ara situats. Aquesta serra forma part del Mantell del Montsec, per on s'ha desenvolupat la totalitat de l'itinerari, des de Benavarri fins aquí.

Per d'altra banda, en aquests indrets es fan clarament palesos els cabussaments dels materials carbonatats mesozoics del Cretàcic cap el Nord, en trobar-nos en el flanc septentrional de l'esmentada Serra del Montsec. 


\section{EN AQUEST INDRET FINALITZA EL RECORREGUT DE L'ITINERARI}

\section{REFERÈNCIES BIBLIOGRÀFIQUES}

GUIMERÀ, J. et altri (1992).- Geologia (II), Història Natural dels Països Catalans, Vol.2, 547 pag. Enciclopèdia Catalana, S.A. Barcelona.

MATA - PERELló, J.M. (1991).- Els Minerals de Catalunya. Arxius de la Secció de Ciències, t. XCIII, 442 pag. Institut d'Estudis Catalans. Barcelona.

MATA - PERELLÓ, J.M. (2005a).- Recorregut geològic i mineralògic per la comarca de la Noguera: des de Bellmunt d'Urgell a Cubells; i des de Camarasa al Pas de Terradets. Inèdit. 10 pàgines. Manresa

MATA - PERELLÓ, J.M. (2005b).- Recorregut de recerca geològica i mineralògica per la comarca de la Ribagorça: des de Caladrons i Ciscar a Queixigar i a la Vall de 1'Tsàbena. Inèdit, 8 pàgines. Manresa

MATA - PERELLÓ, J.M. (2008).- Recorrido desde Chiriveta a Arén, Sopeira y Santorens, a través del Patrimonio Geológico y Minero de la comarca de la Ribagorza. Inédito. 10 páginas. Manresa

RIBA,O. et altri (1976).- Geografia Física dels Països Catalans, Edit. Ketres, 254 pàgines. Barcelona.

\section{TAULES D'EQUVALĖNCIES DELS TERMES TOPONÍMICS UTILITZATS EN AQUEST RECORREGUT, REALITZAT PER LES COMARQUES DE LA RIBAGORÇA I DEL PALLARS JUSSÀ}

\begin{tabular}{|c|c|}
\hline TOPÒNIMS EN LES & TOPÒNIMS EN LENGUIA \\
VARIETATS DIALECTALS DE & CASTELLANA \\
LA RIBAGORÇA & \\
\hline
\end{tabular}

\begin{tabular}{|l|l|}
\hline BAIXA RIBAGORÇA & BAJA RIBAGORZA \\
\hline BENAVARRI & BENABARRE \\
\hline LLITERA & LITERA \\
\hline RIBAGORÇA & RIBAGORZA \\
\hline QUEIXIGAR & CAJIGAR \\
\hline TOLBA & TOLVA \\
\hline XIRIVETA & CHIRIVETA \\
\hline
\end{tabular}

